\title{
Livros Didáticos e Apostilas: o currículo de matemática e a dualidade do ensino médio
}

\author{
Textbooks and Workbooks: The Mathematics Curriculum and the High \\ Schools Ambiguity
}

\author{
Aline Germano Fonseca* \\ Denise Silva Vilela ${ }^{* *}$
}

\begin{abstract}
Resumo
Neste artigo apresentaremos os resultados de uma pesquisa que tem como objetivo comparar apostilas e livros didáticos de Matemática do Ensino Médio, enfocando, a partir da teoria crítica de currículo (SILVA, 2011), conteúdos, sequências e objetivos de ensino expressos nestes materiais. Coloca-se como hipótese a dualidade do Ensino Médio no Brasil, propedêutico ou profíssional, a qual estará expressa também no material didático. As análises revelaram que, apesar do livro didático aparentemente possuir a estrutura e abordagem de conteúdo diferentes das apostilas, os materiais se assemelham nos conteúdos, na sequência deles e na organização disciplinar, o que indica que as novas tendências do ensino, preconizadas no PCN e PNLD-EM, estão superficialmente expressas nos livros didáticos. A hipótese da dualidade se confirma pelo excesso de exercícios nas apostilas, recorrentes "chamadas" e referências a vestibulares, o que remete a um tipo de condicionamento.
\end{abstract}

Palavras-chave: Livros Didáticos. Apostilas. Currículo de Matemática. Ensino Propedêutico ou Profissional.

\begin{abstract}
In this paper we present the results of an analysis that compared high school textbooks and workbooks, emphasizing the critical curricular theories (SILVA, 2011) and the teaching objectives expressed in these materials. Our hypothesis is the High School ambiguity in Brazil, propaedeutic or professional, which would also be expressed in the learning materials. Although, apparently, both materials have different structures and content approaches, the analysis pointed out several similarities in the presented contents, in the sequence and in the disciplinary organization. These similarities indicate that the new teaching proposals suggested by the PCN and PNLD-EM are being superficially adopted by the textbooks. The initial hypothesis confirms itself by the excess of exercises in the workbooks and the constant reference to college's admission examinations that suggests a type of conditioning procedure.
\end{abstract}

Keywords: Textbooks. "Booklets”. Mathematics Curriculum. Propaedeutic or Professional Teaching.

\footnotetext{
* Licenciada em Matemática pela Universidade Federal de São Carlos (UFSCar), São Carlos, SP, Brasil. Endereço para correspondência: Universidade Federal de São Carlos, DME/CECH, Km 235 - Via Washington Luís, CEP: 13565-905, São Carlos, SP, Brasil.E-mail: alinee_fonseca@hotmail.com.

** Doutora em Educação Matemática pela Universidade Estadual de Campinas (UNICAMP). Docente da Universidade Federal de São Carlos (UFSCar), Pesquisadora do Programa de Pós-graduação em Educação da Universidade Federal de São Carlos (UFSCar), São Carlos, SP, Brasil. Endereço para correspondência: Universidade Federal de São Carlos, DME/CECH, Km 235 - Via Washington Luís, CEP: 13565-905, São Carlos, SP, Brasil. E-mail: denisevilela@ufscar.br.
} 


\section{Introdução}

Neste artigo temos o intuito de discutir acerca de dois tipos de materiais didáticos, apostilas e livros didáticos. Discutiremos parte dos resultados alcançados em uma pesquisa realizada nos anos de 2011 e 2012 e que teve como objetivo comparar apostilas e livros didáticos de Matemática do Ensino Médio, buscando, assim, evidenciar suas diferenças e semelhanças e relacioná-las aos objetivos de ensino das instituições que os utilizam.

A motivação inicial para a realização desta pesquisa foi pautada nos seguintes questionamentos: por que atualmente algumas escolas, principalmente as públicas, utilizam livros didáticos e outras, muitas delas particulares, utilizam apostilas? Quais as diferenças e semelhanças entre esses dois tipos de materiais?

Para as análises, foram selecionados livros didáticos e apostilas que datam de 2009, especificamente dois livros didáticos presentes no Programa Nacional do Livro Didático para o Ensino Médio (PNLD-EM) e uma coleção de material apostilado de um grande sistema de ensino do país.

Nosso estudo comparativo teve como base a análise de conteúdo como apresentada por Gil (2006) e aos moldes da teoria proposta por Bardin (2005) e Franco (2008). As análises se apoiaram em um roteiro elaborado a partir da teoria de currículo, conforme as discussões de Silva (2011), e incluiu análise de características gráficas, seleção e sequência de conteúdos e relação com as demais áreas do conhecimento, presença de exercícios de vestibulares, análise de prefácio e sugestões de metodologias diferenciadas de ensino.

Para analisar e compreender a dinâmica que subjaz a utilização dos livros didáticos e das apostilas foi construído um breve histórico político e social dos caminhos que levaram a atual configuração da política educacional, no que diz respeito às políticas de apoio e à análise e distribuição dos livros didáticos. Numa perspectiva de politizar as discussões da Educação Matemática, ao encontro da proposta de Freitag (1989) e de acordo com a noção adotada de currículo, a ideia é explicitar os vínculos entre as esferas política e econômica e estes objetos da cultura escolar.

Discutiremos as teorias do currículo, entre as quais serão destacadas as teorias de Bourdieu no que se refere à noção de habitus e da escola como reprodutora das desigualdades sociais, associando essas teorias ao caráter dual da mesma, profissional e propedêutico.

Neste âmbito, foi realizada a comparação entre os objetivos de ensino expressos em cada tipo de material, ressaltando suas diferenças aparentes e profundas. As análises mostram 
que essas diferenças não são significativas quando comparamos os conteúdos e sua sequência e que as apostilas e os livros didáticos se diferenciam pela forma de abordá-los, sendo que destacamos naquelas o caráter sintético e esquemático. Ademais, a diferença está no excesso de referências ao vestibular contidas no material apostilado, por meio dos exercícios extraídos destes exames e de chamadas constantes que nos parece exercer um papel de condicionamento ou reforço positivo. Apesar de a apostila ganhar popularidade nos últimos anos, veremos que alguns traços, como o tecnicismo da Matemática e ausência de integração com as demais áreas do conhecimento, estão presentes e podem ter vínculos com as concepções do ensino da Matemática da década de 70.

Ao analisar as questões relativas às concepções e os objetivos do ensino expressos nos livros didáticos e nas apostilas do Ensino Médio, nos deparamos com as discussões acerca das atuais demandas de acesso ao Ensino Superior, já que, como veremos posteriormente neste artigo, o vestibular se configurou ao longo da história da educação como um influente da organização desse nível de ensino. O atual Exame Nacional do Ensino Médio (ENEM) pode alterar o quadro de acesso ao Ensino Superior, fato que tende a se refletir nos temas em pauta neste artigo, mas não será privilegiado na presente análise.

\section{O livro didático e suas políticas}

Os materiais didáticos, por terem um papel significativo no processo ensino aprendizagem, têm sido frequentemente discutidos em pesquisas educacionais. Materiais didáticos podem ser os materiais manipulativos, livros didáticos e paradidáticos, apostilas, jogos, CD-ROM, mídias, entre outros. O livro didático ganha destaque diante de sua grande utilização e das políticas educacionais que o envolve.

Essas políticas educacionais que abrangem os livros didáticos e as pesquisas acadêmicas realizadas até então se tornam ainda mais relevantes diante da seguinte afirmação: muitas vezes, o livro didático é o único livro com o qual o aluno tem contato durante toda a trajetória escolar.

\footnotetext{
A formação de leitores no Brasil, por razões históricas, deve muito aos livros escolares. O livro didático, antes adquirido pelos pais ou fornecido por 'caixas escolares', também se tornou, para muitos alunos brasileiros, objeto ritual de acesso à cultura escrita. (MACHADO; FRADE, 2009, p. 1).
}

A linha de estudos em "História das disciplinas escolares", como descrito por Souza e Galvão (2005), determina o livro didático como um objeto cultural, argumentando que os livros didáticos e as semelhanças entre eles, numa certa época, podem trazer indícios sobre 
como era a educação nesse período. Neste sentido, o livro didático é um importante subsídio para entender como foram, e como são, as influências dos movimentos educacionais no ensino da Matemática na Educação Básica.

Além disso, muitos professores planejam suas aulas com base nos conteúdos e sequências apontados pelos livros didáticos. Olhar para o livro didático assumindo esse papel na educação permite entender aspectos importantes do campo educacional e os interesses que se entrecruzam nesta instituição.

A importância do livro didático se confirma na postura política, isso porque, mesmo no período colonial, o governo já acompanhava a produção e seleção de livros didáticos no Brasil. Pode-se dizer que os processos de adoção, avaliação e distribuição dos livros didáticos ocorreram pela primeira vez no Brasil durante o Estado Novo (1937-1945). Como exposto por Oliveira (1984), o Decreto-Lei $\mathrm{n}^{\circ} 1006$, de 1938, criou, no espírito autoritário próprio de um governo ditatorial, a Comissão Nacional do Livro Didático (CNLD). O principal objetivo desta comissão era controlar a produção, a importação e a adoção de livros didáticos. Através das análises dos livros, a CNLD garantia que os exemplares adotados pelas instituições escolares expressassem a ideologia que o governo pretendia embutir na população, mantendo assim o controle da sociedade através da educação. De fato, como descrito por Oliveira (1984, p. 35) a CNLD cumpria seu papel "assegurando que eles [os livros didáticos] atendessem aos propósitos de formação de certo espírito de nacionalidade" e, como principal ênfase, as análises dos livros eram voltadas para aspectos mais políticos do que pedagógicos, resultando em livros com erros pedagógicos e conceituais. Segundo Freitag (1989, p. 13), no artigo 20 do decreto em questão são enumerados onze impedimentos à autorização do livro e somente cinco dizem respeito a questões propriamente didáticas. Neste momento da história da educação podemos notar o controle explícito do governo nos assuntos referentes ao livro didático, confirmando assim seu papel como condutor de ideologias.

A comissão responsável pela análise e distribuição dos livros didáticos sofreu várias alterações no decorrer da história. Destacamos que, em 1976, a Fundação Nacional do Material Escolar incumbiu-se de cuidar dos assuntos dos programas de coedição de obras didáticas. A partir daí, o número de exemplares produzidos aumentou devido à disposição do governo em adquirir parte desses exemplares e distribuir nas unidades federais. Dessa forma, surge um mercado seguro para as editoras: o livro didático que atraía interesses políticos, sociais e econômicos, vindos de grupos governamentais, passa a atrair interesses econômicos de empresários que não possuem vínculos diretos com a educação. 
O atual programa do governo responsável pelos assuntos referentes ao livro didático, o Programa Nacional do Livro Didático (PNLD), movimenta anualmente um grande montante que atrai autores e editoras. Para se ter uma ideia dos valores gastos pelo governo com os programas referentes à distribuição do livro para as escolas públicas, o portal do Fundo Nacional de Desenvolvimento da Educação (BRASIL, 2013) divulgou que os gastos referentes a livros didáticos e obras complementares, no exercício financeiro de 2010, foram de aproximadamente R 184 milhões com obras para o Ensino Médio, além de mais de R\$ 893 milhões com as obras do Ensino Fundamental.

Portanto, se inicialmente mesmo as editoras, detentoras de certo poder dentro desse sistema, se articulavam ao pretendido pelo governo (FREITAG, 1989), hoje, as características e a estruturação do livro didático também foram modificadas de acordo com os objetivos pretendidos por aqueles que detêm as decisões nesse processo.

O PNLD foi criado em 1985 e inclui em suas atribuições elaborar critérios de seleção, de avaliação e é responsável pela distribuição dos livros didáticos. Segundo disposto em documento oficial, Resolução/CD/FNDE no 42 de 28 de agosto de 2012 (BRASIL, 2012, p. 1), e atendendo "a previsão constitucional sobre o fornecimento de material didático", presentes na LDB de 1996, o PNLD distribui livros didáticos gratuitamente nas escolas públicas de Educação Básica atendendo à universalização do ensino, visando "a garantia de oportunidades e a igualdade de condições para o acesso e a permanência dos alunos na escola".

Inicialmente, o objetivo do PNLD era atender alunos do Ensino Fundamental de escolas públicas e, primordialmente, aos componentes básicos, Comunicação e Expressão e Matemática.

A inclusão do Ensino Médio no PNLD se deu muito recentemente, em 2004, e alcançou sua universalidade em 2009. Cabe ressaltar que o PNLD também atende, desde 2007, a Educação de Jovens e Adultos (EJA), por meio do Programa Nacional do Livro Didático para a Educação de Jovens e Adultos (PNLD-EJA). Este material também foi um elemento importante para nossas análises, como veremos posteriormente.

Sobre os procedimentos de análise e adoção dos livros, já em sua criação, o PNLD sugeria que a escolha do livro fosse feita pelo próprio professor, já que seria quem o utilizaria em sala de aula. Antes de chegar às escolas para a escolha dos professores, os livros didáticos passam por uma comissão de "especialistas de cada área" (em geral, pesquisadores de universidades e professores de escolas) a fim de manter a alta qualidade das obras 
participantes do programa. Dentre outras coisas, esses especialistas analisam a existências de erros de forma e/ou conteúdo, indução ao erro, preconceitos e incoerências com os currículos oficiais, alcançando, assim, o nível almejado.

Depois de passar por essa comissão, os livros aprovados e os guias contendo as análises e os comentários da comissão são enviados às escolas para a escolha dos professores. Apesar de os professores poderem optar pelo livro que utilizará, essa escolha se refere a um universo restrito, limitado entre as obras que são enviadas, de editoras específicas e préselecionadas pelo corpo de especialistas, em que o número de professores participantes é muito pequeno em relação ao total que atua na Educação Básica. Ademais, entre as obras disponíveis, a análise e os comentários enviados nos guias de seleção influenciam a decisão dos professores. As editoras também têm papel relevante no processo, já que sua propaganda de divulgação das obras também influencia a escolha do professor:

[As editoras] dispõem de mecanismos mais eficientes de divulgação, de marketing voltados aos setores compradores e consumidores de seus produtos, esses grupos editoriais alcançam grande poder de penetração e circulação entre seus 'clientes'. Essa situação, associada a outros fatores, condiciona, em grande medida, a escolha feita pelo professor (HÖFLING, 2000, p. 168).

O mercado editorial de livros didáticos torna-se suficientemente lucrativo e o PNLD um dos mais abrangentes programas do mundo. Dessa forma, as questões abordadas acima são relevantes para o desenvolvimento deste artigo na medida em que o meio político e econômico leva a uma forma controlada da escolha do livro didático pela escola. A escola, por sua vez, pode também oferecer resistência, direta ou indiretamente, a essa política. $\mathrm{O}$ fato é que muitas escolas públicas têm cedido espaço às apostilas.

\section{Apostilas: tendência tecnicista e os exames vestibulares}

Atualmente, nas escolas de Educação Básica os principais materiais de apoio são os livros didáticos e as apostilas. Os livros são utilizados pela grande maioria das escolas públicas e algumas escolas particulares, enquanto as apostilas são utilizadas pelos grandes sistemas de ensino privado ${ }^{1}$. Neste trabalho, denomina-se sistemas de ensino escolas privadas

\footnotetext{
${ }^{1}$ Recentemente as escolas públicas do Estado de São Paulo também receberam um tipo de material apostilado, organizados em torno do Caderno do Aluno e Caderno do Professor. Elas não serão objeto de análise nesta pesquisa devido as particularidades deste material em relação ao material apostilado, inclusive no que diz respeito à política de implementação. Mesmo assim, o surgimento desse novo tipo de material para o ensino público sugere que as apostilas ganharam destaque dentro do sistema educacional.
} 
que possuem um sistema de franquias por todo o país e utilizam material apostilado. Mas a que se deve a existência desses tipos diferentes de materiais?

Nossa hipótese é que o material didático escolhido como auxílio para a aprendizagem carrega, em sua estrutura, indícios dos objetivos de ensino propostos àqueles que os utilizam. Como ilustração histórica para esta afirmação, podemos citar os materiais didáticos do período de 1860 que exerciam função semelhante às apostilas: eram também baseados nos conteúdos dos exames de admissão no Ensino Superior, na verdade, o material se resumia aos pontos cobrados nos chamados exames parcelados. Valente (2008) apresenta um exemplo de como esses livretos, como eram chamados, eram estruturados: conteúdos apresentados de forma esquemática e compacta. Apesar de a Matemática ser apresentada de uma forma rigorosa do ponto de vista axiomático dedutivo, através de teoremas e definições, a estrutura se assemelha, se considerarmos seu uso e finalidade, ao que, atualmente, caracteriza-se por uma apostila. Esse material surgiu com objetivo claro: auxiliar nos estudos para os exames parcelados, que davam acesso ao Ensino Superior.

Nessa época, século XIX, a estrutura dos níveis escolares não apresentava a divisão do ensino como temos atualmente. Apesar disso, podemos notar que o currículo dos últimos níveis do ensino era determinado pelos conteúdos cobrados nos exames de acesso ao Ensino Superior.

E, de fato, o tipo de material que surge deveria corresponder aos objetivos da educação da época, voltada para a elite que almejava o acesso ao Ensino Superior para a manutenção do status e para se manter no poder, como mostra Ferreira (2010).

O material apostilado, com as características atuais, surgiu em um cenário conturbado no que diz respeito aos processos de acesso ao Ensino Superior. As Reformas Francisco Campos, de 1931, e Capanema, de 1942, promoveram a expansão do ensino e formou novos estudantes aptos ao ingresso no Ensino Superior. Apesar disso, as universidades não possuíam vagas suficientes para incorporar essa demanda e, como resultado, muitos estudantes que eram aprovados não tinham o acesso garantido. Com essa intensificação da procura por vagas nas universidades públicas, em 1968 os exames vestibulares deixam de ter caráter eliminatório e passam a ter caráter classificatório por nota máxima, como previsto pela Lei n. 5540, promulgada pelos militares, conhecida como a Reforma Universitária (FREITAG, 1980, p. 85).

A fim de garantir uma vaga no Ensino Superior, muitos estudantes buscaram como alternativa para uma melhor preparação os cursos preparatórios específicos para este tipo de 
prova, popularmente chamados de 'cursinhos'. Isso acontecia principalmente diante da baixa qualidade da educação pública brasileira na época, bem como pelo aumento da concorrência a uma vaga no Ensino Superior.

O sucesso dessa nova forma de apoio ao ensino aumentou significativamente com o passar dos anos. Os cursinhos, atualmente, se organizam em aulas sobre os conteúdos cobrados nos vestibulares e possuem como principal material didático as apostilas. A efetividade dos cursinhos que era atestada pela imprensa e pelos resultados dos vestibulares, possibilitou o surgimento do que definimos como sistemas de ensino, herdeiros do esquema de aulas apostiladas dos cursinhos. Os sistemas de ensino são redes de escolas particulares que oferecem todos os níveis de ensino, porém com uma promessa de garantia de aprovação nos exames vestibulares.

Essas redes de ensino expandiram suas franquias por todo o país e, mais ainda, venderam sua marca para outras escolas que decidissem usar sua estrutura e seu material didático. O material didático esquematizado em aulas prontas e com o conteúdo dos vestibulares impede que os professores e os próprios alunos percam o foco e, assim, é apresentado como uma ferramenta que favorece as aprovações nos exames.

$\mathrm{Na}$ mesma época em que os cursinhos e os sistemas de ensino ganharam força no cenário educacional, por volta da década de 60 e 70, o ensino da Matemática no Brasil sofreu influência das tendências tecnicistas, tecnicista formalista e tecnicista pragmática, que pretendiam tornar a escola "eficiente" e "funcional" e, além disso, inseri-la "nos modelos de racionalização do sistema capitalista" (FIORENTINI, 1994, p. 46). Traços dessas tendências, como o emprego de técnicas de ensino e o desenvolvimento de habilidades computacionais e manipulativas, são associados ao modelo do material apostilado e será considerada nas análises. Neste sentido, ressaltamos que aspectos da psicologia comportamental, ou behaviorista, que tem o reforço positivo e reforço negativo como mecanismos de condicionamento, são associados a esta tendência.

O território dominado pelas apostilas se expandiu recentemente quando algumas escolas municipais se recusaram a participar do PNLD e adquiriram o material apostilado dos sistemas de ensino. Apesar de o material apostilado custar atualmente cerca de R\$150,00 a $\mathrm{R} \$ 200,00$ por aluno, enquanto o livro didático é distribuído gratuitamente, é crescente a onda de escolas que optam pelo material. O principal argumento de coordenadores e pedagogos é buscar a melhoria da qualidade de ensino e atingir as metas propostas pelo Índice de Desenvolvimento da Educação Básica (IBED) em um período mais curto. Este fato evidencia 
a dependência das escolas do material didático e, particularmente, a influência das avaliações externas no Ensino Básico.

Note que, além da importância do material e do que a escolha entre livro didático e apostila pode sugerir, este fato nos diz que as novas parcerias público-privadas têm sido feitas, do ponto de vista governamental, com extrema liberdade. Dessa forma, o governo transfere ao setor privado seus deveres. Os sistemas de ensino expandem seus horizontes: antes controlavam o sistema educacional particular praticamente como um todo e agora passam a controlar uma parcela da educação pública.

\begin{abstract}
As informações coletadas indicam uma tendência crescente nos municípios paulistas, sobretudo naqueles com até 50 mil habitantes, considerados de pequeno porte, a buscar suporte político e pedagógico para o atendimento educacional sob sua responsabilidade junto a empresas privadas que oferecem serviços e produtos, tais como materiais didáticos para alunos e professores, incluindo apostilas e CDROOMs, formação docente em serviço e monitoramento do uso dos materiais adquiridos. Parece-nos que tais empresas, mais do que meras fornecedoras de materiais e equipamentos, passam a incidir sobre o desenho da política educacional local e sobre a organização do trabalho docente e administrativo desenvolvido em cada uma das unidades de ensino da rede pública, razão pela qual se tornam parceiras dos governos municipais (ADRIÃO et al., 2009, p. 802).
\end{abstract}

A mídia tem desempenhado seu papel no marketing dos sistemas de ensino apresentando os resultados de escolas públicas que utilizaram o material apostilado.

\footnotetext{
Alunos de escolas públicas municipais de São Paulo que usam apostilas de sistemas de ensino estatais ou privados se saem melhor que os demais na Prova Brasil [...] o uso de material elaborado por sistemas de ensino tem crescido em São Paulo, e hoje $46 \%$ dos municípios do Estado utilizam o material substituindo ou complementando livros didáticos. São, em sua maioria, cidades de pequeno porte (GOIS, 2010, p. 1).
}

Nessas condições, voltamos às atenções para o material apostilado: os conteúdos são diferentes daqueles que encontramos nos livros? O que diferencia estes materiais?

Para melhor compreensão dos resultados da pesquisa em questão é necessário, anteriormente, atentarmos para as teorias do currículo apresentando as principais ideias que se tornaram fio condutor de nossas análises das apostilas e LD.

\title{
4 As teorias do currículo e a escola profissionalizante reprodutora
}

Nesta sessão pretende-se articular uma teoria crítica do currículo (SILVA, 2011) com a discussão acerca dos objetivos de ensino, propedêutico e profissionalizante, e o papel do vestibular e dos livros didáticos. A nossa ideia de currículo inclui suas formas de expressão e componentes tais como políticas públicas, avaliações externas, vestibular e livros didáticos.

O currículo vem sofrendo alterações de acordo com os interesses políticos e 
econômicos envolvidos no contexto de determinada época; o currículo trouxe e traz indícios desses interesses e das crenças que transitam entre os campos educacional, político e social.

\begin{abstract}
O currículo é entendido como um instrumento político que seleciona e privilegia um conhecimento em detrimento do outro, ele não é neutro, mas resultado de seleções definidas a partir de lutas sociais e conduz valores relativos a interesses particulares, ou seja, ele está intimamente relacionado ao poder: O currículo é um dos locais privilegiados onde se entrecruzam saber e poder, representação e domínio, discurso e regulação. É também no currículo que se condensam relações de poder que são cruciais para o processo de formação de subjetividades sociais. Em suma, currículo, poder e identidades sociais estão mutuamente implicados. O currículo corporifica relações sociais (SILVA, 1995, p. 200).
\end{abstract}

Para nossas discussões vamos considerar, a partir de Silva (2011), as teorias do currículo subdividas em tradicionais, críticas e pós-críticas. As teorias tradicionais, como ficaram conhecidas, inicialmente estiveram preocupadas em discutir aspectos metodológicos e de conteúdo, em que as questões centrais são o que ensinar e como ensinar. Durante a década de 60, quando eclodiu uma série de movimentos revolucionários pelo mundo, inclusive no Brasil, as teorias tradicionais do currículo também passaram a sofrer críticas. Se as teorias tradicionais são apresentadas como neutras e científicas, excluindo das discussões as relações de poder, as teorias críticas e pós-críticas afirmam que nenhum currículo é neutro e, por isso, devem ser consideradas as conexões entre o saber, a identidade e o poder.

O currículo, nessa perspectiva, tem como uma de suas discussões o questionamento sobre qual tipo de indivíduo se pretende formar. Nas palavras de Silva $(2011$, p. 15) "o que eles ou elas devem se tornar? Afinal, o currículo busca precisamente modificar e adequar as pessoas que vão 'seguir' aquele currículo". Nesse sentido, são colocadas em pauta, nas teorias denominadas críticas, questões predominantemente sociais e suas relações com a educação escolar, a reprodução social, as relações de poder, o capitalismo, os aspectos ideológicos, etc.

Para discutir as teorias críticas, Silva (2011) faz referência às ideias de vários pesquisadores da sociologia dentre eles Paulo Freire, Louis Althusser, Michael Young, Pierre Bourdieu e Jean Claude Passeron. Estes caracterizam a escola como parte das relações sociais, políticas e econômicas, reforçando relações de poder e reproduzindo as desigualdades sociais. Os principais pontos presentes nessas discussões apontam a escola como uma das bases que "sustentam" o sistema capitalista, baseado na dominação de classes, transmitindo ideologias ${ }^{2}$ de maneira neutra ou "natural".

Segundo Silva (2011, p. 16), as teorias críticas, assim como as pós-críticas, estão "preocupadas com as conexões entre o saber, identidade e poder". O que as difere é que nas

\footnotetext{
2 Sabendo que "ideologia" é um termo bem difundido no senso comum, devemos esclarecer que, do ponto de vista acadêmico, está associado à teoria de Marx e Engels, a qual tem como referência as classes sociais.
} 
teorias pós-críticas o poder passa a ser descentralizado e o multiculturalismo torna-se peça fundamental para as discussões.

O poder não tem mais um único centro, como o Estado, por exemplo. O poder está
espalhado por toda a rede social. As teorias pós-críticas desconfiam de qualquer
postulação que tenha como pressuposto uma situação finalmente livre de poder. [...]
o conhecimento é parte inerente do poder. Em contraste com as teorias críticas, as
teorias pós-críticas não limitam a análise do poder ao campo das relações
econômicas do capitalismo. Com as teorias pós-críticas o mapa do poder é ampliado
para incluir processos de dominação centrados na raça, na etnia, no gênero e na
sexualidade (SILVA, 2011, p. 148).

A questão social e educacional aqui considerada envolve especificamente a divisão entre ensino propedêutico e profissional, bem como a reprodução social peculiar nesta temática. Em nossas análises discutiremos particularmente o âmbito das teorias críticas de currículo, tendo como referência aspectos da teoria de Bourdieu.

Bourdieu, ao considerar as forças do campo e não as diferentes classes sociais, coloca como central a noção de habitus. Interpretando Silva, mediante a teoria bourdiesiana, podemos dizer que o currículo é um espaço em que circulam diferentes capitais, de intensidade proporcional à força (ou poder) dos agentes do campo educacional correspondente.

Buscamos nas análises aspectos explícitos e implícitos que pudessem indicar indícios ideológicos ou, com os termos de Bourdieu, traços do capital valorizado e habitus relativos, sobretudo, à continuação dos estudos/ensino propedêutico ou a profissionalização em ambos os materiais analisados.

Na obra "A reprodução", de Bourdieu e Passeron (2009), a ideologia de escola libertadora é questionada e a escola é entendida como uma instituição que conserva as estruturas da sociedade, como um mecanismo de conservação social, isto é, contribui para manter a ordem social hierarquizada. Segundo esta teoria, na escola se privilegia um habitus de classe, ou seja, se promove a cultura da classe dominante como legítima e inquestionável:

\footnotetext{
[...] tal sistema [de ensino tradicional] contribui de maneira insubstituível para perpetuar a estrutura das relações de classe e ao mesmo tempo para legitimá-la ao dissimular que as hierarquias escolares que ele produz reproduzem hierarquias sociais (BOURDIEU; PASSERON, 2009, p. 244-245).
}

Bourdieu (1983, p. 61) considera o habitus como "sistemas de disposições duráveis", uma integração das experiências passadas de modo a funcionar como uma matriz de percepções, de apreciações e ações.

Incutindo um habitus, o material didático pode induzir um aluno a determinado futuro profissional, já que o material didático conduz um currículo que, segundo discutido em Silva 
(2011, p. 15), transmite ideologias, com o intuito de "modificar aqueles que o seguem". Usar apostila ficou associado ao destino universitário. Além de direcionar, o currículo transmite "neutralidade", isto é, ele transparece ser independente e estar acima de interesses sociais, políticos, etc. Isto se realiza por meio de argumentos da naturalização que coloca o currículo escolhido como o legítimo e o único universalmente válido. Com isso, a cultura da classe dominante é promovida como a cultura legítima e, portanto, superior e verdadeira.

Segundo Lugli (2007, p. 34), assim como se tornou "natural que a sociedade e a escola classifiquem as pessoas, também parece natural que cada um se ajuste àquilo que lhe surge (porque é natural) como possibilidade de destino". Deste modo, o estudante passa a ajustar as percepções que tem de si próprio com as percepções das condições de vida que tem, conformando-o de seu destino. Nesse sentido, a autora reforça que se para "alguns é inquestionável a continuidade dos estudos em nível superior, para outros, seguir em funções menos prestigiosas no sistema ocupacional parece a única saída possível e desejável” (LUGLI, 2007, p. 34).

Diante disso, pretendemos verificar qual o papel do material didático com relação as discussões curriculares, tendo como referência a teoria crítica discutida acima, principalmente no que se diz respeito ao ensino propedêutico e profissional.

As orientações curriculares governamentais assumem um papel de destaque em nossas discussões, já que as atuais demandas de acesso ao Ensino Superior e o próprio PNLD têm sofrido mudanças impulsionadas por elas. Deste modo, na próxima seção discutiremos alguns aspectos das principais orientações curriculares propostas pelo MEC e pelas Diretrizes Curriculares Nacionais para o Ensino Médio (DCNEM, 2011).

\section{As atuais propostas e orientações curriculares para o Ensino Médio sob a ótica dos objetivos de ensino propedêutico e profissionalizante}

Neste artigo, como o material selecionado para análise é proveniente do Ensino Médio, devemos ter em mente que este nível de ensino tem sido influenciado pelo vestibular, que aponta na direção de dar continuidade aos estudos, seguindo a linha do propedêutico. Os conteúdos deste nível de ensino presentes nos livros didáticos e nas apostilas, bem como seu currículo, nos darão indícios dos objetivos de ensino almejados para este nível. Segundo Fernandes (2010, p. 11), o "poder dos conteúdos nos ajuda na busca de atingir nossos objetivos na educação. Não faz muito sentido pensar em conteúdo sem pensar em objetivos, 
são duas coisas que devem andar juntas".

Atualmente, o PNLD tem como base as orientações curriculares propostas pelo MEC. Na ocasião da pesquisa, os Parâmetros Curriculares Nacionais (PCN), que são orientações curriculares e metodológicas, vigoravam dentre as discussões sobre o tema. Diante do montante considerável envolvido no processo do PNLD, as editoras seguem essas propostas com o intuito de potencializar suas chances de participar do programa. Consequentemente, as orientações dos PCN têm, por essa via, uma forma de acesso ao meio escolar e, apesar de ser apenas orientações, ele se configura de modo impositivo.

Os PCN (BRASIL, 2000), as Orientações Curriculares para o Ensino Médio (OCME) (BRASIL, 2006) e as Diretrizes Curriculares Nacionais para o Ensino Médio (DCNEM) (BRASIL, 2011) têm norteado mudanças tanto de conteúdo como metodológicas para o Ensino Médio. Neste artigo, ao mencionar "orientações curriculares" estamos nos referindo aos PCN, mas em aspectos que não destoam das OCME e das DCNEM. Essas mudanças curriculares foram influenciadas pelo desenvolvimento da tecnologia e pela dinâmica atual que envolve, também, a organização do mundo do trabalho. Mas quais os objetivos de ensino pretendidos por essas propostas? Segundo exposto no PCN, e também DCNEM (BRASIL, 2011), o objetivo do ensino é garantir tanto a "terminalidade" dos estudos e o ingresso no mercado de trabalho, quanto a continuação do mesmo e um possível ingresso na vida acadêmica:

\footnotetext{
O Ensino Médio passa a ter a característica de terminalidade, o que significa assegurar a todos os cidadãos a oportunidade de consolidar e aprofundar os conhecimentos adquiridos no Ensino Fundamental; aprimorar o educando como uma pessoa humana, possibilitar o prosseguimento dos estudos; garantir a preparação básica para o trabalho e a cidadania; dotar o educando dos instrumentos que o permitam ‘continuar estudando' (BRASIL, 2000, p. 9).
}

Essas disposições estão apoiadas na LDB 9394/96 e parecem agradar a todos de forma que o futuro pós Ensino Médio seja efetivamente decidido pelo próprio estudante.

Entretanto, a análise de Bittencourt (2004), especificamente sobre os PCN, indica a prevalência da sintonia das propostas educacionais com os interesses políticos e econômicos, voltados ao mercado de trabalho. O princípio norteador dos PCN é a integração curricular que pode ser percebida, como mostra a autora, na abordagem por competências como princípio organizacional do currículo ou ainda na divisão dos conteúdos do Ensino Médio em três áreas: Linguagens, Códigos e suas Tecnologias; Ciências Humanas e suas Tecnologias; Ciências da Natureza, Matemática e suas tecnologias.

Lopes, citado por Bittencourt (2004, p. 75), acredita que a integração curricular no 
PCN "consiste em uma recuperação de idéias educacionais que visavam atender as demandas da produção taylorista e fordista, mas recolocadas no contexto de produção capitalista atual", e, com isso, esse tipo de organização curricular indica a "valorização de princípios formativos que levam a uma formação profissional devidamente adequada às exigências do mercado", reforçando assim o caráter profissionalizante que a proposta de integração dos PCN carrega em seu discurso libertador.

Apesar disso, segundo as DCNEM (BRASIL, 2011, p. 29), o Ensino Médio têm sua identidade definida "na superação do dualismo entre propedêutico e profissional". Essas diretrizes apresentam algumas discussões sobre a permanência do ensino propedêutico e profissional, afirmando que até a LBD ser outorgada houve muitas tentativas de superar essa dualidade. Segundo o disposto nesse documento, os estudantes do Ensino Médio muitas vezes pretendem ingressar no mercado de trabalho e, por isso, o Ensino Médio deve também atender a essa demanda. A ideia é ultrapassar o dualismo de forma que ele não seja propedêutico em sua completude, mas também não passe a ser somente profissionalizante.

\begin{abstract}
A definição da identidade de Ensino Médio como etapa conclusiva da Educação Básica precisa ser iniciada mediante um projeto que, conquanto seja unitário em seus princípios e objetivos, desenvolva possibilidades formativas com itinerários diversificados que contemplem as múltiplas necessidades socioculturais e econômicas dos estudantes, reconhecendo-os como sujeitos de direitos no momento em que cursam esse ensino (BRASIL, 2011, p. 29).
\end{abstract}

Quanto à abordagem metodológica, as DCNEM, assim como os PCN e as OCEM, sugerem a integração curricular, através de atividades contextualizadas e que incluam aspectos do cotidiano. O que difere essas daquela é quanto a sua aplicação. As DCNEM propõem que deve haver dois momentos: um disciplinar para aprofundar os conceitos e outro integrador com atividades interdisciplinares.

Segundo o exposto no documento da OCEM (BRASIL, 2006), essas orientações surgiram diante da necessidade de discutir/esclarecer alguns pontos presentes nos PCN (BRASIL, 2000). Nesse documento a proposta permanece como no PCN e DCNEM no que diz respeito ao princípio integrador e a contextualização da Matemática. Sobre esta disciplina são apresentadas formas para se trabalhar com o conteúdo, discussões sobre o projeto pedagógico e a organização curricular.

Por exemplo, quanto às formas de se trabalhar com o conteúdo, conforme exposto no documento, resolver equações exponenciais deve ser evitado, a não ser que "haja um propósito maior" e quando o assunto for progressões geométricas e aritméticas "devem-se evitar as exaustivas coletâneas de cálculos que fazem simples usos de fórmulas” (BRASIL, 
2006, p. 75). Estas orientações nos sugerem a tentativa de ultrapassar o tecnicismo que está presente nas apostilas.

Neste sentido, levando em consideração que os livros didáticos têm por base as orientações curriculares aqui discutidas, sobretudo o PCN, os materiais, livros didáticos e apostila, são diferentes, já que provém de objetivos diferentes. De fato, se as apostilas focam o vestibular, tendo uma tendência tecnicista, os livros didáticos e os PCN devem estar consoantes com as demandas do mercado de trabalho (BITTENCOURT, 2004). Como parte da análise apresentada a seguir, veremos como essas tendências e orientações estão expressas no material didático.

\section{Análise dos livros didáticos e apostilas}

Os materiais foram analisados, num primeiro momento, separadamente, o que é mantido nesta exposição. Foi utilizada a análise de conteúdo que, segundo Gil (2006), é a técnica que melhor possibilita a descrição e a análise dos conteúdos explícitos e implícitos nas fontes utilizadas.

Dentre outras coisas, foram analisadas características gráficas, relações dos conteúdos de Matemática com temas de outras áreas, metodologias sugeridas pelo autor, quantidade e característica dos exercícios (retirados de vestibular, contextualizados, interpretativos ou mecânicos), aprofundamento e nível de rigor dos conteúdos, sequência em que os conteúdos aparecem e distribuição dos mesmos.

A escolha dos livros didáticos para as análises teve como critério estar incluído no PNLD de 2009. Denotaremos os livros didáticos por L(1) e L(2) e as apostilas por A. Cabe ressaltar que os livros inteiros foram analisados e que estes são referentes aos três anos do Ensino Médio, constituindo-se de um volume único.

Os livros didáticos analisados apresentam bastante semelhança tanto na estrutura como nas propostas dos autores, o que era de se esperar já que ambos participam de um mesmo programa e devem atender as mesmas exigências. Analisamos os prefácios em ambos os livros e sobre isso, nota-se que as apostilas não possuem prefácio.

No L(1) o autor apresenta o livro como um material "flexível e adaptável a diferentes contextos escolares e situações de aprendizagem" (L(1), 2009, p. 4). Além disso, é enfatizada a utilização de tópicos que tem aplicabilidade no cotidiano do aluno. A flexibilidade e adaptação do material nos rementem aos objetivos da educação, de forma que o livro possa 
ser usado para diferentes finalidades. As características explicitadas pelo autor sugerem adequação às propostas dos PCN e das OCEM.

O autor do L(2), por sua vez, enfatiza que o livro foi escrito com o intuito de aprofundar os conhecimentos do Ensino Fundamental e para que o aluno desenvolva a capacidade de aplicar esses conhecimentos para resolver problemas do mundo real. Neste sentido, ambos, L(1) e L(2), sugerem uma adequação ao perfil de cidadão que o mercado de trabalho atual demanda, com habilidades para resolver problemas.

Nos dois prefácios, tanto L(1) como L(2), observamos que os autores se preocupam em apresentar um livro que possa ser usado para os diferentes objetivos de ensino e em dar ênfase que o livro apresenta contextualização, aspectos cotidianos e interdisciplinaridade, buscando a integração dos conteúdos.

O segundo aspecto analisado referiu-se aos conteúdos de cada livro e a sequência em que os conteúdos são apresentados. Ambos os livros seguem uma ordem semelhante, separando o livro em Álgebra, Estatística e Probabilidade, Geometria Analítica, Geometria Euclidiana e Trigonometria e, dentro de cada uma dessas áreas, a sequência dos conteúdos não apresenta diferenças significativas.

Com relação aos aspectos gráficos, os dois livros utilizam de estrutura parecida: texto apresentado em duas colunas, utilização de cores, gráficos e imagens ilustrativas. Além disso, nos livros didáticos o desenvolvimento da teoria é precedido por uma "motivação" ao estudo, geralmente alguma situação contextualizada ou que utiliza aspectos históricos.

Nos livros de Ensino Médio regular L(1) e L(2), algumas propostas metodológicas como, por exemplo, a História da Matemática foram inseridas com caráter apenas informativo aos finais de capítulos, sem fazer relação com os conceitos matemáticos desenvolvidos anteriormente. Os estudos de Pimentel (2012) mostram que, especificamente, a história da Matemática nos livros didáticos do Ensino Fundamental é apresentada de maneira superficial, dissociada e anedotizada, o que se verifica também nos livros didáticos analisados nesta pesquisa.

O material apostilado, por sua vez, teve sua escolha justificada por ser, esse material, bastante representativo diante dos sistemas de ensino de todo o país, e também considerando que a estrutura das apostilas, independente do sistema a que pertence, é bastante semelhante. Esse material é bastante extenso, composto de várias apostilas que são entregues ao aluno de maneira fragmentada, três apostilas por bimestre. O material principal é composto por 12 apostilas, de forma que a cada bimestre o aluno recebe três apostilas: uma de teoria, uma de 
exercícios a serem feitos em sala com acompanhamento do professor e uma de tarefas, contendo os exercícios que os alunos farão em casa. Além desse material, os alunos recebem o gabarito das apostilas tarefas, uma revisão geral ao final do ano e algumas fichas-resumo que tem uma estrutura mais compacta do que o resto do material, sugerindo que seja o componente final para a fixação dos conceitos e dos algoritmos para os exames vestibulares.

Ao analisar a estrutura das apostilas, notamos que esse material é mais conciso e possui aspectos tecnicistas, se compararmos aos livros didáticos. Não há presença de qualquer tipo de contextualização, interdisciplinaridade e/ou outras metodologias propostas pelas orientações curriculares. Além disso, os exercícios são em sua grande maioria, cerca de 70\%, retirados ou adaptados de vestibulares. O material em si lembra o aluno a todo o momento que o foco está no exame vestibular. De fato, não há surpresa ao se fazer essa constatação já que os objetivos de ensino daqueles que utilizam as apostilas em seus sistemas de ensino, desde sua criação, é a aprovação nos exames vestibulares. A surpresa está em perceber que não é o conteúdo que os difere, mas a estrutura de condicionamento presente nas apostilas e ausente nos livros didáticos.

Estruturalmente, as apostilas mantêm os conteúdos divididos em módulos (aulas), de forma que a cada módulo o aluno se depare com a teoria e os exercícios que serão resolvidos em sala de aula. Um recurso bastante utilizado nesse material são os quadros de destaque, que enfatizam conceitos e fórmulas importantes, e são utilizados como auxílio para a memorização. A teoria é apresentada através de definições, de fórmulas e, raramente, de demonstrações dos teoremas matemáticos, sendo ausentes, até mesmo, as discussões sobre as relações dos diferentes tópicos da matemática.

Quanto à análise comparativa entre os livros didáticos e as apostilas, estes materiais pareciam inicialmente muito diferentes. Enquanto nas apostilas os textos são apresentados de maneira compacta, os livros apresentam textos explicativos mais longos, com inserção de aspectos do cotidiano e a menção à metodologias diferenciadas, o que nos sugeriu a possibilidade de o livro didático se configurar como um material interdisciplinar.

Essa hipótese se mostrou ingênua na medida em que analisamos de maneira mais detalhada cada conteúdo contido em ambos os materiais e mediante comparação com livros didáticos da Educação de Jovens e Adultos (EJA), selecionados pelo primeiro PNLD-EJA. Casale (2011) realizou um estudo que versou sobre a análise de uma coleção de livros didáticos de Matemática para EJA, mostrando que este material apresenta uma proposta mais interdisciplinar se os compararmos com os livros didáticos do Ensino Regular analisados em 
nossas pesquisas. Ocorre que, nos livros didáticos do EJA, os conteúdos matemáticos e de outras áreas são abordados através de temas geradores como, por exemplo, cidadania. Neste caso, a temática cidadania é o ponto de partida para discutir e resolver problemas de geometria euclidiana plana, de estatística, de probabilidade e também, sobre este tema, desenvolve-se as disciplinas de Geografia, História, etc. Devido a essa organização, desde o sumário sentimos dificuldade em estabelecer em quais páginas encontraríamos determinado tópico matemático. Esse estudo se mostrou importante para as nossas análises de forma a compreendermos melhor a noção de interdisciplinaridade por meio dessa objetivação. Podemos dizer que os livros analisados do PNLD-EM se alinham às características da sequência linear, própria da abordagem disciplinar, conforme discutido por Bittencourt (2004).

Olhando para o livro didático, apesar de aparentemente possuir uma abordagem mais contextualizada, na verdade, essa abordagem se mostra artificial. Os aspectos cotidianos e as tentativas de contextualização aparecem dissociados dos conteúdos matemáticos, de maneira que esses aspectos surgiam mais como enfeites ou motivações para a aprendizagem de determinados conteúdos do que de fato promoviam uma relação entre as situações cotidianas e contextualizadas com a Matemática.

Além disso, nos livros didáticos, a Matemática é apresentada com um apelo à utilidade, isto é, o material tenta oferecer subsídios para que o aluno se convença de que os conteúdos matemáticos escolares servem para alguma coisa. Em contrapartida, nas apostilas, a Matemática se coloca como um fim em si, ou insiste em repetir que aprender Matemática é útil para o vestibular. O foco das apostilas é que o aluno se aproprie de ferramentas suficientes para realizar a maior quantidade possível de exercícios e, assim, treinar para o exame vestibular.

Continuando as análises, levamos em consideração a quantidade de páginas reservadas para determinados conteúdos bem como a quantidade de exercícios disponíveis sobre cada assunto. Isso porque prevalece a ideia de que a aprendizagem da Matemática se dá por meio da realização de exercícios e solução de problemas. A tabela abaixo, produto de nossas análises, mostra a distribuição dos conteúdos por assunto em cada um dos materiais analisados, indicando que, desse ponto de vista, os conteúdos abordados e a extensão deles nos materiais são bastante semelhantes. 
Tabela 1 - Porcentagem da distribuição dos conteúdos por assunto

\begin{tabular}{c|c|c|c}
\hline Conteúdos & L(1) & L(2) & A \\
\hline Álgebra, Estatística e Probabilidade & $59 \%$ & $63 \%$ & $58 \%$ \\
\hline Geometria $^{3}$ & $26 \%$ & $26 \%$ & $31 \%$ \\
\hline Trigonometria & $15 \%$ & $11 \%$ & $11 \%$ \\
\hline
\end{tabular}

Fonte: elaborada pelas autoras.

Note que a porcentagem da distribuição de exercícios por assunto é bem próxima entre os materiais. Isto sugere que não há uma tendência em beneficiar determinado conteúdo de modo que justifique afirmar, deste ponto de vista, a existência de discrepâncias entre os materiais.

Por outro lado, o que diferencia cada material analisado é a quantidade de exercícios de vestibular em comparação com a quantidade de exercícios. A partir de nossas análises contruímos o gráfico abaixo que mostra essa relação em cada material analisado.

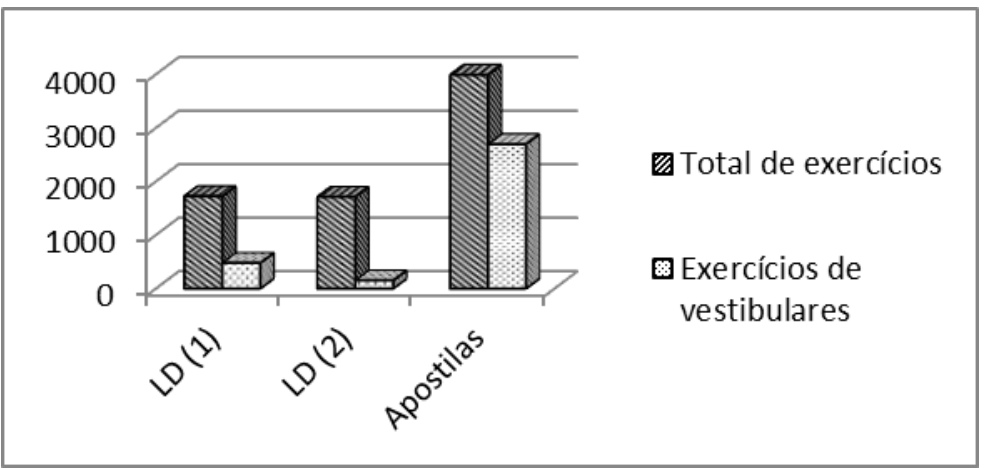

Figura 1 - Gráfico da quantidade total de exercícios e dos exercícios retirados de vestibulares dos materiais analisados

Fonte: elaborada pelas autoras

Com base no gráfico acima, a diferença na quantidade de exercícios é significativa: as apostilas apresentam quase o triplo da quantidade proposta pelos livros, os quais possuem, entre eles, quantidades semelhantes de exercícios. Quanto aos exercícios retirados e/ou adaptados de vestibulares com relação à quantidade total de exercícios, os livros didáticos possuem cerca de $28 \%$ (L(1)) e $9 \%$ (L(2)), enquanto as apostilas possuem cerca de $70 \%$.

Diante disso, a maior quantidade de exercícios de vestibulares no material apostilado, em uma análise mais aprofundada, traz indícios da ideologia ou, usando o termo de Bourdieu (1998), traz a indicação de um habitus.

Quanto ao tipo dos exercícios, nos livros didáticos eles aparecem obedecendo uma proposta de aumento gradativo de dificuldade, do mais simples para o mais complexo. Isso

\footnotetext{
${ }^{3}$ Em geometria estão inseridas tanto a geometria euclidiana quanto a geometria analítica.
} 
também ocorre nas apostilas, porém, elas propõem inicialmente uma grande quantidade de exercícios mecânicos, isto é, que exigem apenas a aplicação de algoritmos, seguidos de exercícios retirados de diversos exames vestibulares. Retomando Fiorentini (1994, p. 48) ao descrever as características tecnicistas, associamos essas características ao desenvolvimento de habilidades computacionais e manipulativas, "capacitando o aluno para a realização de exercícios ou problemas-padrão".

Deve ser ressaltado que, nos exercícios retirados de vestibulares o nome da instituição que aplica o exame é escrito antecedendo ao enunciado do exercício. Isto nos sugere que o aluno não perca o foco e saiba o tipo de prova que irá prestar, sugere também que esta é uma maneira de direcionar o aluno para o Ensino Superior, condicionando-o para esta finalidade. Ao lançar mão dessas chamadas, a apostila induz o estudante ao nível superior e não ao mercado de trabalho. Além disso, os alunos que utilizam esse material, em sua grande maioria, são provenientes das classes com maior poder aquisitivo e, se levarmos em conta a teoria crítica de Bourdieu, a qual associamos o ensino propedêutico e profissional, pode-se ver aí estratégias de conservação das diferenças sociais.

\section{Considerações finais}

Analisando o currículo não só em seus aspectos de conteúdo, sequência e metodologia, mas também ideológicos e influências políticas (PCN/PNLD), pode ser dito que a questão da dualidade de ensino, propedêutico e profissional, está expressa nestes materiais.

As análises revelam que os materiais didáticos analisados não possuem diferenças significativas no que diz respeito aos conteúdos apresentados e apesar de possuírem diferenças tímidas quanto à metodologia empregada, as diferenças mais expressivas são na estrutura do material e nos objetivos do ensino.

As apostilas apresentam os conteúdos de maneira concisa, sem muitos textos explicativos e sem relação com os demais temas da Matemática ou outras áreas do conhecimento. Não há preocupação em atender as metodologias propostas nas orientações curriculares. No que diz respeito às ideias e valores implícitos, é interessante notar que as apostilas utilizam de ferramentas para voltar o foco dos estudantes para o vestibular, como por exemplo, a inclusão de grande quantidade de exercícios retirados dos exames. Nesse sentido, pode-se dizer que os alunos que utilizam apostilas são condicionados ao Ensino Superior, ou que o habitus relativo ao caminho que devem seguir vai sendo confirmado e inculcado. Ao 
nos remeter às discussões de Bourdieu sobre habitus, e sobre o ensino propedêutico, reforçamos a visão da escola como reprodutora das desigualdades sociais. Especificamente, quanto ao ensino propedêutico, se entendido em sua dimensão do prosseguimento ou continuidade dos estudos, a escola, em particular o Ensino Médio apostilado e privado, representa um mecanismo de transformação, ou valorização, da herança cultural em capital.

Os livros didáticos, por sua vez, trazem indícios mais claros de interesses na formação profissional. Estes apresentam uma tentativa de implantar as propostas metodológicas dos PCN, como resolução de problemas, história da Matemática e contextualização. Apesar de essa tentativa surgir mais como enfeite do que de maneira efetiva, a linguagem e a argumentação utilizada nos livros didáticos evocam principalmente a contextualização e a resolução de problemas, metodologias que potencializam as competências e habilidades visadas pelo mercado de trabalho (BITTENCOURT, 2004).

Concluímos que os materiais didáticos analisados, não através da exclusão ou inclusão de determinados conteúdos e sim através de sua estruturação, reproduzem certas ideias, como sugerido por Freitag (1989). Em certa medida, podemos dizer que as apostilas e os livros didáticos têm disseminado ideologias diferentes, propedêutica e profissional, e diferentes enfoques. Um sugere uma Matemática contextualizada e mantém-se mais alinhada às demandas do mercado de trabalho. A outra, as apostilas, apresenta a Matemática de maneira tecnicista e como um fim, sem se preocupar em apresentar possíveis "utilidades": o fim é o próprio vestibular.

Neste sentido, retomando Silva (2011), a pesquisa alcançou de modo fecundo uma compreensão da noção de currículo que transcende a seleção de conteúdos, sequências e propostas metodológicas: currículo como um espaço de força política e de interesses. $\mathrm{O}$ material didático se configura como disseminador de ideologias e direciona o futuro dos estudantes que os utilizam.

\section{Referências}

ADRIÃO, T; et al. Uma modalidade peculiar de privatização da educação pública: a aquisição de "sistemas de ensino" por municípios paulistas. Educação e Sociedade, Campinas, v. 30, n. 108, p. 799-818, out. 2009.

BARDIN, L. Análise de conteúdo. Tradução de Luís Antero Reto e Augusto Pinheiro. São Paulo: Edições 70, 2005.

BITTENCOURT, J. Sentidos da integração curricular e o ensino de matemática nos parâmetros curriculares nacionais. Zetetiké, Campinas, v. 12, n. 22, p. 71-88, jul./dez. 2004. 
BORDIEU, P.; PASSERON, J.C. A reprodução: elementos para uma teoria do sistema de ensino. Tradução de P. G. da Silva. Lisboa: Vega, 2009.

BOURDIEU, P. Questões de Sociologia. Rio de Janeiro: Marco Zero, 1983.

BOURDIEU, P. Escritos de educação. Petrópolis: Vozes, 1998.

BRASIL. Decreto-Lei n ${ }^{\mathbf{1}} \mathbf{. 0 0 6}$, de 30 de Dezembro de 1938. Estabelece as condições de produção, importação e utilização do livro didático. Disponível em: <

http://www2.camara.leg.br/legin/fed/declei/1930-1939/decreto-lei-1006-30-dezembro-1938-350741publicacaooriginal-1-pe.html>. Acesso em: 29 jul. 2014.

BRASIL. Ministério da Educação e do Desporto. Secretaria de Educação Fundamental. Parâmetros curriculares nacionais. Brasília: MEC, 2000.

BRASIL. Orientações curriculares para o ensino médio. 2006. Disponível em:

$<$ http://portal.mec.gov.br/seb/arquivos/pdf/book_volume_02_internet.pdf $>$. Acesso em: 04 fev. 2014.

BRASIL. Diretrizes curriculares nacionais para o ensino médio. 2011. Disponível em:

$<$ http://portal.mec.gov.br/index.php?option=com_content\&id=12992>. Acesso em: 04 fev. 2014

BRASIL. Resoluções sobre o programa nacional do livro didático. 2012. Disponível em:

$<$ http://www.fnde.gov.br/fnde/legislacao/resolucoes/item/3758>. Acesso em: 09 jun. 2013.

BRASIL. Portal do MEC. Fundo Nacional do Desenvolvimento da Educação. Brasíllia, 2013.

Disponível em: <http://www.fnde.gov.br/component/k2/item/518-

hist\%C3\%B3rico?highlight=YToxOntpOjA7czo0OiJwbmxkIjt9>. Acesso em: 5 jun. 2013.

CASALE, S. R. C. G. O enfoque da matemática em uma coleção de livros didáticos do PNLD-

EJA. Monografia apresentada como trabalho final do Curso de Especialização em Educação de Jovens e Adultos, UFSCar, 2011.

FERNANDES, J. A. B. A seleção de conteúdos: o professor e sua autonomia na construção do currículo. São Carlos: EdUFSCar, 2010. (Coleção UAB-UFSCar).

FERREIRA JR. A. História da educação brasileira: da colônia ao século XX. São Carlos: EdUFSCar, 2010. (Coleção UAB-UFSCar).

FIORENTINI, D. Rumos da pesquisa brasileira em educação matemática: o caso da produção científica em cursos de Pós-Graduação. 1994. (301+113) f. Tese (Doutorado em Educação: Metodologia de Ensino) - Universidade Estadual de Campinas, Campinas, 1994.

FRANCO, M. L. P. B. Análise de conteúdo. 3. ed. Brasilia: Liber Livro, 2008. 79 p. (Série Pesquisa; v.6)

FREITAG, B. Escola, estado e sociedade. 4. ed. São Paulo: Moraes, 1980. (Coleção educação universitária).

FREITAG, B; MOTTA, V. R.; COSTA, W. F. O livro didático em questão. 3. ed. São Paulo: Cortez,1989.

GIL, A. C. Métodos e técnicas de pesquisa social. 5. ed. São Paulo: Atlas, 2006. 
GOIS, A. Apostila melhora nota de aluno em SP. Folha online. 29 jun. 2010. Disponível em: $<$ http://www1.folha.uol.com.br/fsp/cotidian/ff2906201001.htm>. Acesso em: 5 dez. 2011.

HÖFLING, E. M. Notas para a discussão quanto à implementação de programas do governo: em foco o programa nacional do livro didático. Educação e Sociedade, Campinas, v. 21, n. 70, abr. 2000.

LUGLI, R. S. G. A construção social do indivíduo. Educação, São Paulo, v. 5, n. 2, p. 26-35, jun. 2007.

MACHADO, M. Z. V.; FRADE, I. C. A. S. Os programas do livro: do acesso ao uso. Letra A: o jornal alfabetizador, Belo Horizonte, v. 5, n. 19, ago./set. 2009. Disponível em:

$<$ http://www.ceale.fae.ufmg.br/nomade/midia/docs/230/php5aSfuQ.pdf $>$. Acesso em: 22 jun. 2010.

OLIVEIRA, J. B. A.; GUIMARÃES, S. D. P.; BOMÉNY, H. M. B. A política do livro didático. São Paulo: Summus; Campinas: EdUNICAMP, 1984.

PIMENTEL, G. A história da geometria em livros didáticos. 2012. 120 f. Dissertação (Mestrado em Educação) - Programa de Pós-Graduação em Educação da Universidade Federal de São Carlos, São Carlos, 2012.

SILVA, T. Documentos de identidade: uma introdução às teorias do currículo. 3. ed. Belo Horizonte: Autêntica, 2011.

SOUZA, M. J.; GALVÃO, A. M. O. História das disciplinas escolares e história da educação: algumas reflexões. Educação e Pesquisa, São Paulo, v. 31, n. 3, p. 391-401, set./dez. 2005.

VALENTE, W. R. Quem somos nós professores de matemática? Caderno Cedes, Campinas, v. 28, n. 74, p. 11-23, jan./abr. 2008. 